\title{
Molecular and clinical characteristics of very long-chain acyl-CoA dehydrogenase deficiency
}

\author{
A single-center experience in Saudi Arabia
}

Amal Alhashem, MD, FMG, Sarar Mohamed, FRCPCH, MD, Manal Abdelraheem, MD, MRCPCH, Bushra AlGufaydi , MD, ABP, Aida Al-Aqeel, FRCP, FACMG.

\begin{abstract}

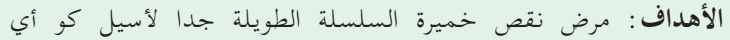

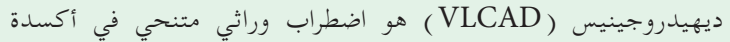

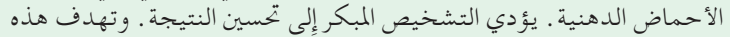

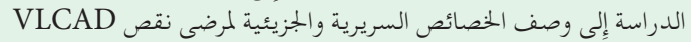

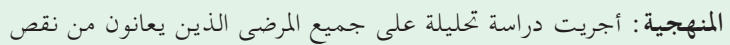

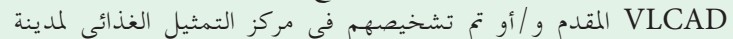

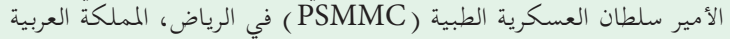

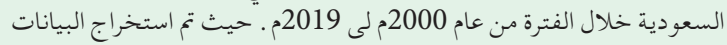

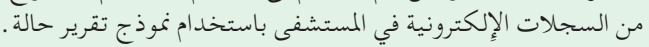

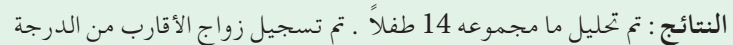

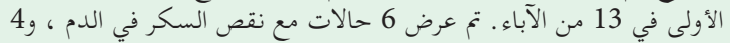

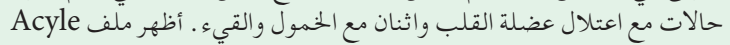
تائي Carnitine

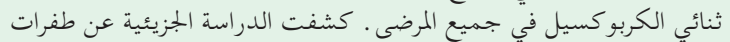

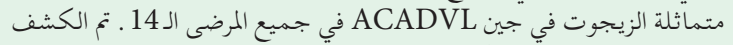

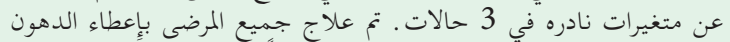

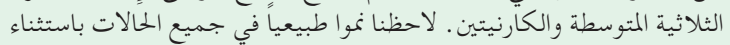

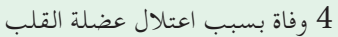

الحخلاصة : شُخِصت معظم المرضى في هذه المجمدوعة في فترة الولادة.

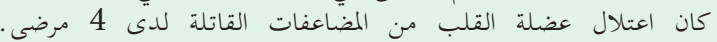
وتوسعنا في وصف المتغيرات الجزيئية الجديدة المكاعنشفة المناتلة
\end{abstract}

Objectives: To describe the clinical and molecular characteristics of patients with very long-chain acyl-CoA dehydrogenase (VLCAD) deficiency.

Methods: A retrospective observational cross-sectional analysis was conducted on all patients with VLCAD deficiency at (Genetic/Metabolic Section), Prince Sultan Military Medical City (PSMMC), Riyadh, Saudi Arabia from 2000 to 2019. Demographic, clinical, and laboratory data were abstracted from the electronic hospital records using a case report form.
Results: A total of 14 children were analyzed. Six presented with hypoglycemia, 4 with cardiomyopathy, and 10 had rhabdomyolysis. Five patients had early onset severe phenotype, while 9 had mild form. The molecular study revealed homozygous mutations in $A C A D V L$ in all 14 patients. Three variants were not reported before. All patients were treated with medium-chain triglyceride and carnitine. Ten patients are alive and have normal development, while 4 died.

Conclusion: Most of the patients in this cohort presented in the neonatal period either by newborn screening or clinically with hypoglycemia, cardiomyopathy, and rhabdomyolysis. The new molecular variants detected in this study broaden the genetic spectrum of VLCAD deficiency in Saudi Arabia.

Keywords: clinical characteristics, clinical, molecular, Saudi Arabia, VLCAD deficiency

Saudi Med J 2020; Vol. 41 (6): 590-596 doi: 10.15537/smj.2020.6.25131

From the Department of Pediatrics (Alhashem, Abdelrahim, AlGufaydi, Al-Aqeel, Mohamed), Prince Sultan Military Medical City; from the Department of Pediatrics (Alhashem, Mohamed); from the Department of Anatomy and Embryology (Al-Aqeel), College of Medicine, AlFaisal University; from Prince Abdullah bin Khalid Celiac Disease Research Chair (Mohamed), King Saud University, Riyadh, Kingdom of Saudi Arabia; and from the Department of Biochemistry and Molecular Biology (Al-Aqeel), College of Medicine, American University of Beirut, Beirut, Lebanon.

Received 7th April 2020. Accepted 20th May 2020.

Address correspondence and reprint request to: Dr. Sarar Mohamed, Prince Sultan Military Medical City, Riyadh, Kingdom of Saudi Arabia. E-amil: srarmohamed@psmmc.med.sa ORCID ID: https://orcid.org./0000-0002-7393-5064 
$\mathrm{V}$ ery long-chain acyl-CoA dehydrogenase (VLCAD) deficiency (OMIM\#201475) is an autosomal recessive disorder of fatty acid oxidation with significant variability in the severity and timing of its clinical presentation. ${ }^{1}$ The incidence of VLCAD deficiency world-wide varies from 1:30,000 to 1:100,000 live births. ${ }^{1}$ In Saudi Arabia, an incidence of 1:37,000 has been reported. ${ }^{2}$ The disease is the result of mutations in the acyl-CoA dehydrogenase very long-chain $(A C A D V L)$ gene, causing deficiency of VLCAD, which catalyzes the initial step of mitochondrial $\beta$-oxidation of long-chain fatty acids. ${ }^{3}$ This leads to the accumulation of high plasma levels of long-chain acylcarnitine conjugates, especially the tetradecenoyl (C14:1) acylcarnitine. ${ }^{3}$

Very long-chain acyl-CoA dehydrogenase deficiency is clinically heterogeneous and can exhibit a wide range of clinical outcomes, including a severe neonatal-onset disease associated with high mortality, and a high incidence of cardiomyopathy. ${ }^{4-6}$ The infantile-onset form of VLCAD deficiency usually presents with hypoketotic hypoglycemia and rarely cardiomyopathy and has low mortality. ${ }^{4}$ The adult-onset form affects the skeletal muscle, primarily causing rhabdomyolysis, and myoglobinuria, which is usually triggered by exercise or fasting. ${ }^{1,2,4}$ In addition, VLCAD deficiency can be diagnosed by newborn screening (NBS), and is typically identified through high C14:1 acylcarnitine. ${ }^{2}$ In the United States of America (USA), large multicenter NBS studies reported positive predictive values of $20 \%$ to $30 \%$ for the detection of VLCAD deficiency. ${ }^{7,8}$ Several studies reported the outcome of NBS and have shown that most of the babies appeared to be asymptomatic on follow-up. ${ }^{6,9}$ Different variants have been reported in $A C A D V L$ that cause variable clinical presentations. Nevertheless, some reports documented apparent phenotype/genotype correlation. ${ }^{1,4-6}$

As VLCAD deficiency is a rare disease and there is insufficient data available from the Middle East, we report the clinical and molecular characteristics of patients with VLCAD deficiency who attended our center. ${ }^{10}$

Methods. This retrospective cross-sectional review of 14 genetically confirmed cases of VLCAD deficiency attending the metabolic center at Prince Sultan Military

Disclosure. Authors have no conflict of interests, and the work was not supported or funded by any drug company.
Medical City (PSMMC), Riyadh, Saudi Arabia. It is a tertiary health care facility with more than 1000 beds that serves a large population in the Kingdom of Saudi Arabia. Data for all patients attending the facility from 2000 to 2019 were analyzed with special emphasis on the clinical and molecular characteristics. Demographic, clinical, and laboratory data were gathered from the electronic hospital records using a case report form. The neuro-developmental assessment was carried out by the attending pediatrician according to the clinical examination findings.

The diagnosis of VLCAD deficiency among the studied cases was suspected by the presence of high C14:1 acylcarnitine and confirmed by the identification of biallelic pathogenic variants in the ACADVL gene. Molecular testing was carried out by $A C A D V L$ gene sequencing, target mutation or whole exome sequencing depending on the clinical scenario, the family history, and the access to the test. Other supporting investigations like creatinine phosphokinase, glucose, liver function and echocardiography were recorded. All patients were supplemented with L-carnitine $(50 \mathrm{mg} / \mathrm{kg}$ body weight/ day) and medium-chain triglyceride (MCT) formula, with added corn starch when needed.

We grouped the mode of presentation of the patients in 3 entities, routine NBS, high risk NBS, and clinical presentation. Routine NBS is part of the national NBS which is performed between day 2 and 5 after birth. High risk screening was carried out for infants who have a sibling with VLCAD deficiency. It is usually carried out in the first week of life. The third group includes infants who presented with symptoms suggestive of VLCAD deficiency such as hypoglycemia and cardiomyopathy that lead to the diagnosis. Rhabdomyolysis is defined as peak creatinine phosphokinase more than 1000 U/L1. Metabolic decompensation is referred to acute metabolic acidosis, shock and multiorgan failure. ${ }^{1}$ The severity of VLCAD deficiency is classified as early onset severe type, mild childhood, and adult onset type according to the previous studies. ${ }^{1,4}$

This study was approved by the PSMMC Institutional Research Board. Ethical consideration to ensure confidentiality and privacy of the collected data were observed.

Statistical analysis. The statistical analysis was carried out using Statistical Package for Social Sciences for Windows, version 22 (IBM Corp, Armonk, NY, USA). Data are reported as frequencies and percentages. A $p$ value of $<0.05$ was considered as significant.

Results. Fourteen patients with VLCAD deficiency confirmed by molecular analyses were included in this 
study. Eight patients diagnosed in the neonatal period, 5 in infancy, and one at 2 and half years (Table 1). Six patients diagnosed by high risk NBS, 2 by routine NBS, one was diagnosed antenatally by amniocentesis, and 5 presented clinically with symptoms suggestive of VLCAD deficiency. Four patients have cardiomyopathy, 6 have hepatomegaly, 6 have hypoglycemia, 9 have lactic acidosis, and 10 rhabdomyolysis. Four patients had metabolic decompensation with metabolic acidosis, shock and multi-organ failure. Five patients have early-onset severe phenotype and 9 have mild childhood phenotype. None of our patients have adult onset type. Consanguinity was found in 13 patients (93\%); all patients' parents were first degree cousins. Family history of a sibling with VLCAD deficiency was observed in 11 patients representing $79 \%$ of the cohort.

Table 1 shows the molecular spectrum of the patients with VLCAD deficiency. All of the patients (100\%) were homozygous for variants in the $A C A D V L$ gene, 8 were missense variants, 3 nonsense, 2 frameshift mutations, and one deletion. Two variants were novel: c.1557delG (p. S520vfs) and c.779C>T (p.T260M) (Tables $1 \& 2$ ).
Family segregation and In Silico prediction studies (Mutation Taster, www.mutationtaster.org; SIFT, http:// sift.jcvi.org/) predict the variants to be deleterious.

All patients had normal neuro-developments according to their age. Four patients died $(28.5 \%)$ in the first 2 years of life. All have severe early-onset phenotype and 3 of them had cardiomyopathy that was of infantile onset, while the fourth had metabolic decompensation with metabolic acidosis, shock, and multi-organ failure (Table 1). Two of the deceased had frameshift variant with stop codon, one had nonsense, and one had missense variant (Table 1). Most of the patients with the mild childhood phenotype have missense variant, while most of the early-onset severe phenotype have nonsense, frameshift and deletion variants, $p=0.036331$ as shown in Table 3. In contrast, no significant correlation was found between the genotype and the survival (Table 4) or between the mode of the diagnosis and the severity of the phenotype (Table 5).

Discussion. Very long-chain acyl-CoA dehydrogenase deficiency is a major metabolic disorder

Table 1 - Clinical, biochemical, and molecular characteristics of 14 patients with VLCAD deficiency.

\begin{tabular}{|c|c|c|c|c|c|c|c|c|c|c|c|c|c|c|c|c|c|c|c|}
\hline Case & $\begin{array}{l}\text { Current } \\
\text { age } \\
\text { (year) }\end{array}$ & Gender & $\begin{array}{c}\text { Age at } \\
\text { symptom } \\
\text { onset }\end{array}$ & $\begin{array}{l}\text { Mode of } \\
\text { presen- } \\
\text { tation }\end{array}$ & $\begin{array}{l}\text { Hepato- } \\
\text { megaly }\end{array}$ & $\begin{array}{l}\text { Cardio- } \\
\text { myopathy }\end{array}$ & $\begin{array}{l}\text { Rhabdo- } \\
\text { myolysis }\end{array}$ & $\begin{array}{l}\text { Hypo- } \\
\text { glycemia }\end{array}$ & $\begin{array}{c}\text { C14 } \\
(<0.6 \\
\text { umol/l) }\end{array}$ & $\begin{array}{l}\text { C14:1 } \\
(<0.39)\end{array}$ & $\begin{array}{c}\text { Lactic } \\
\text { acid } \\
(0.5-2.2 \\
\mathrm{mmol} / \mathrm{L})\end{array}$ & $\begin{array}{c}\text { Peak } \\
\text { CPK } \\
(50-190 \\
\text { U/L })\end{array}$ & $\begin{array}{c}\text { Metabolic } \\
\text { decom- } \\
\text { pensation }\end{array}$ & $\begin{array}{c}\text { Pheotype } \\
\text { severity }\end{array}$ & $\begin{array}{l}\text { Genetic } \\
\text { testing }\end{array}$ & Variant & $\mathrm{FH}$ & $\begin{array}{l}\text { Consan- } \\
\text { guinity }\end{array}$ & $\begin{array}{l}\text { Out- } \\
\text { come }\end{array}$ \\
\hline 1 & 7 & M & 2.5 & Clinical & Yes & No & Yes & Yes & 0.345 & 1.12 & 1.3 & 2550 & No & Mild & WES & $\begin{array}{l}\text { c.898_900del, } \\
\text { p.E300del }\end{array}$ & Yes & Yes & alive \\
\hline 2 & - & M & $1 \mathrm{D}$ & $\begin{array}{l}\text { High risk } \\
\text { NBS }\end{array}$ & Yes & Yes & Yes & No & 2.4 & 1.8 & 7.8 & 24641 & Yes & Severe & $\begin{array}{c}\text { Gene } \\
\text { sequence }\end{array}$ & $\begin{array}{l}\text { c. } 1557 \mathrm{del} \text {, } \\
\text { p.S520vFs* }\end{array}$ & Yes & Yes & $\begin{array}{l}\text { died at } \\
2 \text { years }\end{array}$ \\
\hline 3 & - & M & $1 \mathrm{D}$ & $\begin{array}{l}\text { High risk } \\
\text { NBS }\end{array}$ & Yes & Yes & Yes & Yes & 4.9 & 2.41 & 8.7 & 4303 & Yes & Severe & FAO panel & $\begin{array}{l}\text { c. } 1557 \mathrm{del} \\
\text { p.S520vFs* }\end{array}$ & Yes & Yes & $\begin{array}{l}\text { died at } \\
2 \text { years }\end{array}$ \\
\hline 4 & 3 & M & $2 \mathrm{M}$ & $\begin{array}{l}\text { High risk } \\
\text { NBS/ } \\
\text { antenatal }\end{array}$ & No & No & Yes & No & 2.17 & 3.00 & 3.2 & 35594 & No & Mild & $\begin{array}{c}\text { Target } \\
\text { mutation }\end{array}$ & $\begin{array}{l}\text { c.1313G }>A \text {, } \\
\text { p.G438E }\end{array}$ & Yes & Yes & alive \\
\hline 5 & - & F & $2 \mathrm{M}$ & Clinical & No & Yes & Yes & Yes & 1.30 & 1.05 & 3.9 & 3592 & Yes & Severe & $\begin{array}{c}\text { Gene } \\
\text { sequence }\end{array}$ & $\begin{array}{c}\text { c. } 1313 \mathrm{G}>\mathrm{A}, \\
\text { p.G438E }\end{array}$ & Yes & Yes & $\begin{array}{c}\text { died at } \\
3 \mathrm{M}\end{array}$ \\
\hline 6 & 4 & M & $2 \mathrm{M}$ & $\begin{array}{l}\text { High risk } \\
\text { NBS }\end{array}$ & No & No & No & No & 1.3 & 0.3 & 5.7 & 568 & No & Mild & $\begin{array}{c}\text { Gene } \\
\text { sequence }\end{array}$ & $\begin{array}{l}\text { c. } 779 \mathrm{C}>\mathrm{T} \text {, } \\
\text { p.T260M }\end{array}$ & Yes & no & alive \\
\hline 7 & 8 & F & $2 \mathrm{M}$ & $\begin{array}{l}\text { High risk } \\
\text { NBS }\end{array}$ & No & Yes & Yes & No & 3.4 & 1.2 & NA & 4786 & No & Severe & $\begin{array}{c}\text { Gene } \\
\text { sequence }\end{array}$ & $\begin{array}{l}\text { c. } 65 \mathrm{C}>\mathrm{A}, \\
\text { p.S22* }\end{array}$ & Yes & Yes & alive \\
\hline 8 & 13 & F & $4 \mathrm{M}$ & Clinical & Yes & No & Yes & Yes & 1.45 & 0.75 & 5 & 82703 & No & Mild & $\begin{array}{c}\text { Gene } \\
\text { sequence }\end{array}$ & $\begin{array}{l}\text { c. } 1748 \mathrm{C}>\mathrm{T} \\
\text { p.S583L }\end{array}$ & Yes & Yes & alive \\
\hline 9 & 3 & F & $8 \mathrm{M}$ & Clinical & No & No & Yes & Yes & 0.17 & 0.29 & 1.6 & 2208 & No & Mild & WES & $\begin{array}{c}\text { c. } 1310 \mathrm{~A}>\mathrm{C} \\
\text { p.E437A }\end{array}$ & no & Yes & alive \\
\hline 10 & 10 & M & $4 \mathrm{M}$ & $\begin{array}{l}\text { High risk } \\
\text { NBS }\end{array}$ & Yes & No & No & No & NA & 1.8 & 3.4 & 581 & No & Mild & FAO Panel & $\begin{array}{c}\text { c. } 1748 \mathrm{C}>\mathrm{T} \\
\text { p.S583L }\end{array}$ & Yes & Yes & alive \\
\hline 11 & 2 & M & $1 \mathrm{D}$ & $\begin{array}{l}\text { Routine } \\
\text { NBS }\end{array}$ & No & No & Yes & No & 1.4 & 0.8 & 1.2 & 3649 & No & Mild & WES & $\begin{array}{c}\text { c. } 134 \mathrm{C}>\mathrm{A}, \mathrm{p} . \\
\text { S45* }\end{array}$ & Yes & Yes & alive \\
\hline 12 & 8 & F & $3 \mathrm{M}$ & Clinical & Yes & No & No & Yes & 1.5 & 2.31 & 5.0 & 583 & No & Mild & $\begin{array}{c}\text { Gene } \\
\text { sequence }\end{array}$ & $\begin{array}{l}\text { c. } 1175 \mathrm{~A}>\mathrm{C}, \\
\text { p.E392A }\end{array}$ & no & Yes & alive \\
\hline 13 & 1 & F & $\begin{array}{l}\text { Asymp- } \\
\text { tomatic }\end{array}$ & $\begin{array}{l}\text { Routine } \\
\text { NBS }\end{array}$ & No & No & No & No & NA & 0.11 & 4.9 & 162 & No & Mild & $\begin{array}{c}\text { Gene } \\
\text { sequence }\end{array}$ & $\begin{array}{l}\text { c. } 1700 \mathrm{G}>\mathrm{A}, \\
\text { p.R567Q }\end{array}$ & no & Yes & alive \\
\hline 14 & - & M & $1 \mathrm{M}$ & $\begin{array}{l}\text { High risk } \\
\text { NBS }\end{array}$ & No & No & Yes & No & 1.41 & 1.12 & 3.4 & 12703 & Yes & Severe & $\begin{array}{c}\text { Gene } \\
\text { sequence }\end{array}$ & $\begin{array}{l}\text { c. } 65 \mathrm{C}>\mathrm{A}, \\
\text { p.S22* }\end{array}$ & Yes & Yes & $\begin{array}{l}\text { died } \\
\text { at } 1.7 \\
\text { years }\end{array}$ \\
\hline
\end{tabular}


Table 2 - Genotypic features of 14 patients with VLCAD deficiency.

\begin{tabular}{|c|c|c|c|c|c|c|}
\hline $\begin{array}{l}\text { DNA cucleotide } \\
\text { change }\end{array}$ & Protein & n $\quad(\%)$ & $\begin{array}{c}\text { Variant } \\
\text { characteristic }\end{array}$ & Zygosity & Reference sequences & PMID ref \\
\hline c. $65 \mathrm{C}>\mathrm{A}$ & p.S22* & $2(16.7)$ & Known & Homozygous & NM_000018.4 & $\begin{array}{l}\text { Watanabe et al }{ }^{11} \\
\text { PMID: } 10790204\end{array}$ \\
\hline c. $1313 \mathrm{G}>\mathrm{A}$ & p.G438E & $2(16.7)$ & Not reported & Homozygous & NM_000018.4 & - \\
\hline c. $1557 \mathrm{delG}$ & p.S520Vfs* & $2(16.7)$ & Novel & Homozygous & - & - \\
\hline c. $779 \mathrm{C}>\mathrm{T}$ & p.T260M & $1 \quad(8.3)$ & Known & Homozygous & NM_000018.3 & $\begin{array}{l}\text { Andresen et } \mathrm{al}^{2} \\
\text { PMID: } 8845838\end{array}$ \\
\hline c. $1748 \mathrm{C}>\mathrm{T}$ & p.S583L & $2(16.7)$ & Known & Homozygous & NM_000018.4 & $\begin{array}{c}\text { Souri et } \mathrm{al}^{13} \\
\text { PMID: } 9599005\end{array}$ \\
\hline c. $1310 \mathrm{~A}>\mathrm{C}$ & p.E437A & $1 \quad(8.3)$ & Known & Homozygous & NM_001270447 & $\begin{array}{l}\text { Hisahara et al } \mathrm{al}^{13} \\
\text { PMID: } 25843429\end{array}$ \\
\hline c. $134 \mathrm{C}>\mathrm{A}$ & p.S $45^{*}$ & $1 \quad(8.3)$ & Known & Homozygous & NM_001270447.1 & $\begin{array}{l}\text { Watanabe et al }{ }^{11} \\
\text { PMID: } 10790204\end{array}$ \\
\hline c. $1175 \mathrm{~A}>\mathrm{C}$ & p.E392A & $1 \quad(8.3)$ & Novel & Homozygous & NM_001033859 & - \\
\hline c. $1700 \mathrm{G}>\mathrm{A}$ & p.R567Q & $1 \quad(8.3)$ & Known & Homozygous & NM_000018.3 & $\begin{array}{c}\text { Schiff et } \mathrm{al}^{15} \\
\text { PMID: } 23480858\end{array}$ \\
\hline c.898_900del & p.E300del & $1 \quad(8.3)$ & Known & Homozygous & NM_001270447.1 & $\begin{array}{c}\text { Isackson et } \mathrm{al}^{16} \\
\text { PMID: } 23169530\end{array}$ \\
\hline
\end{tabular}

VLCAD: very long-chain acyl-CoA dehydrogenase, DNA: deoxyribonucleic acid, PMID: PubMed reference number

Table 3 - Phenotype/genotype correlation of 14 patients with very longchain acyl-CoA dehydrogenase deficiency.

\begin{tabular}{lccc}
\hline Genotype & $\begin{array}{c}\text { Mild } \\
\text { phenotype }\end{array}$ & $\begin{array}{c}\text { Severe } \\
\text { phenotype }\end{array}$ & $P$-value \\
\hline Nonsense/frameshift/deletion & 2 & 4 & 0.036331 \\
Missense & 7 & 1 & \\
Total & 9 & 5 & \\
\hline
\end{tabular}

Table 4 - Correlation of genotype with survival in 14 patients with very long-chain acyl-CoA dehydrogenase deficiency.

\begin{tabular}{lccc}
\hline Genotype & Alive & Died & $P$-value \\
\hline Nonsense/frameshift/deletion & 3 & 3 & \\
Missense & 7 & 1 & 0.124283 \\
Total & 10 & 4 & \\
\hline
\end{tabular}

of mitochondrial fatty acid beta-oxidation, with significant variability in the severity and timing of its clinical presentation. In this report, we present our experience with 14 patients and compare their clinical phenotype and genotype with the previous studies.

In this cohort, 9 patients were diagnosed by NBS while the rest presented clinically with symptoms suggestive of VLCAD deficiency. This is unlike the experience from the USA where the majority of patients with VLCAD deficiency were picked up by NBS as described in publications from large multistate NB-S consortium. ${ }^{5.6}$ This could be explained by the fact that our universal NBS started in 2011; therefore, some of
Table 5 - Correlation of the mode of presentation with the severity of the phenotype in 14 patients with very long-chain acyl-CoA dehydrogenase deficiency.

\begin{tabular}{lccc}
\hline $\begin{array}{l}\text { Mode of } \\
\text { presentation }\end{array}$ & $\begin{array}{c}\text { Mild } \\
\text { phenotype }\end{array}$ & $\begin{array}{c}\text { Severe } \\
\text { phenotype }\end{array}$ & $P$-value \\
\hline Newborn screening & 5 & 4 & 0.360387 \\
Clinical presentation & 4 & 1 & \\
Total & 9 & 5 & \\
\hline
\end{tabular}

the older patients before the screening era presented clinically. However, some of our patients before the implementation of the national NBS were diagnosed by high risk NBS when family history of VLCAD deficiency was reported. The data from the large NBS programs from the United States, Australia, and Europe indicate that most of the detected infants tend to have mild form of the disease..$^{5-9}$ In contrast, infants diagnosed by NBS in our cohort have comparable mild and severe forms. This is because some of these patients were diagnosed by high risk NBS. In fact, one of the 2 infants diagnosed by routine NBS is still asymptomatic and the other infant has mild phenotype. Generally, NBS seems to improve the short-term outcome of VLCAD deficiency; however, there is a lack of data on the long-term outcome of individuals diagnosed during NBS. ${ }^{4}$ This is partly due to the logistical and patientprivacy issues faced by the screening institutes when attempting to collect clinical information from a large cohort of patients seen by different care providers.

As documented in the previous work, VLCAD deficiency is classified into 3 phenotypes according to 
the disease severity. ${ }^{1,4,5,9,10}$ One third of our patients have severe early-onset phenotype presenting with cardiomyopathy and metabolic decompensation, while the rest have mild childhood type characterized by hypoglycemia, hepatomegaly, and rhabdomyolysis. In contrast to this, the majority of infants with VLCAD deficiency reported from the western countries and Australia have mild childhood phenotype and some have adult-onset type. ${ }^{5-9}$ Interestingly, none of our patients had adult-onset disease. These patients may be missed by the referring physicians as presentation of these patients tend to be mild and nonspecific, mainly as rhabdomyolysis. Also, the awareness on this rare genetic disease among adult physicians is probably low.

The molecular basis of VLCAD deficiency is diverse, with $>200$ mutations reported in the literature. ${ }^{1}$ The genotype of patients in this cohort showed that all of them were homozygous for variants in the $A C A D V L$ gene. This is not unusual for autosomal recessive disorders in a highly consanguineous population like Saudi Arabia. We found significant correlation between the genotype and the severity of the phenotype in this study, $(p=0.036331)$. We detected a spectrum of variants in this cohort: mostly missense, but also nonsense stop codon and frameshift variants. This is unlike the previous Saudi report in 37 patients with VLCAD deficiency, which showed a single founder nonsense mutation in exon 2 of $A C A D V L$ c. $65 \mathrm{C}>\mathrm{A}, \mathrm{p}$. Ser22X in 31 patients $(83.7 \%) .{ }^{10}$ We found this variant in only 2 of our patients. This could possibly be explained by the tribal make-up of the population served by different institutes where this study and the previous study were conducted. Our institute serves military personnel and their families from different parts of the country. This might account for the variable variants detected in our study. The nonsense variant c. $65 \mathrm{C}>\mathrm{A}, \mathrm{p} . \mathrm{S} 22^{*}$ results in truncated protein, and therefore leads to null enzyme level. This explains the severe phenotype and the high mortality reported with this variant in the previous Saudi study. ${ }^{10}$ Similarly, our 2 patients with this variant had severe early-onset phenotype. One died at 1.7 years of age in a peripheral hospital with severe metabolic decompensation and multi-organ failure. Unfortunately, echocardiography was not carried and therefore cardiomyopathy was not confirmed. The second one is currently 8 years old with cardiomyopathy, her neurodevelopment was normal. Therefore, this study confirmed that the nonsense variant c.65C>A, p.S22* is associated with severe early onset phenotype.

The second and the third deceased subjects in this cohort are siblings who presented with an early-onset severe phenotype with cardiomyopathy, and were homozygous for the variant: c.1557delG (p.520Vfs*). This stop codon novel variant is expected to result in null enzyme activity and therefore explains the associated severe disease and death.

The fourth deceases subject in this study presented at 2 months of age with an early-onset severe phenotype with cardiomyopathy and died at 3 months with multi-organ failure. She was homozygous for the missense variant c.1313G $>A$ (p.G438E). To our knowledge, this variant has not been previously reported in the literature in individuals with $A C A D V L$ related disease. ${ }^{1-4,6,8,10-16}$ In Clin Var, a report of this variant predicts that the amino acid residue p.Gly438 of the $A C A D V L$ protein has been highly conserved during evolution. In Silico tools (PolyPhen-2. SIFT and Mutation Taster) predict the p.Gly438Glu change to be probably damaging, deleterious, and disease causing. The younger brother of this deceased infant was diagnosed antenatally with the same variant and started carnitine and medium-chain triglyceride formula since birth. He is currently 3 years old and have mild phenotype with recurrent rhabdomyolysis associated mostly with viral infections. He has no hypoglycemia, hepatomegaly or cardiomyopathy. It is not clear why these 2 siblings have the same variant but different phenotype. The only difference was the prospective treatment of the brother since birth. However, we cannot make a firm statement regarding this association from one family. This observation needs to be confirmed in other families with the same variant.

Also, another 2 years old patient in this cohort diagnosed by routine NBS and treated prospectively has mild phenotype with rhabdomyolysis and no cardiomyopathy. Interestingly, this boy carries a homozygous nonsense variant (c.134C>A,p.S45*). This variant is expected to cause null enzyme activity and therefore severe disease. It is not clear whether this mild phenotype resulted from the prospective treatment since birth or not. Larger prospective studies may clarify these findings regarding the phenotype/genotype correlation. Nevertheless, our findings indicate that null mutations are likely to be associated with severe phenotype. On the other hand, 7 of our 8 patients with missense mutations have mild phenotype. This is expected as the missense variants are likely to have residual enzyme activity.

Patient 9 had homozygous variant, c.1310A $>C$ p.(Glu437Ala), which causes an amino acid change from Glu to Ala at position 437. This variant has already been described as disease-causing for VLCAD dehydrogenase deficiency by Hisahara et al ${ }^{14}$ (PMID: 25843429). The authors reported that this variant was detected in heterozygous state in a patient with 
elevation of serum C14:1 revealed by tandem mass spectrometry. In the same patient, high performance liquid chromatographic analysis showed decreased production of 2-hexadecenoyl-CoA (C16:1) from palmitoyl-CoA (C16:0), indicating the defect of VLCAD activity. The authors proposed this variant to have a dominant negative effect and reported it as variant of uncertain significance. Our patient with the same variant in homozygous state presented with recurrent hypoglycemia and rhabdomyolysis. Her C14:1 was high and urine organic acid showed dicarboxylic aciduria. This clinical and biochemical profile in addition to the family segregation is consistent with VLCAD deficiency. Furthermore, in Silico tools (Polyphen, SIFT, mutation Taster) predict this variant to be probably damaging, deleterious and disease causing respectively. We think this variant should be considered as likely pathogenic.

The variant c.848T $>C$ (p.V283A) has been reported as the most frequent mutation in VLCAD deficient patients in the west. ${ }^{1,4}$ This variant is likely to cause mild childhood phenotype. We did not observe this variant in our cohort. It was also not detected in other Saudi studies..$^{10}$ The mortality rate in this study was $28.5 \%$. In a previous Saudi study, the mortality rate was $62.1 \%$ among the 37 studied VLCAD deficiency patients. ${ }^{10}$ The higher rate of death reported in that study was attributed to the high rate of cardiomyopathy that reached $59.4 \%$. Similarly, the mortality rate of VLCAD deficiency has been reported to be as high as $75 \%$ in patients clinically diagnosed during pre-NBS. ${ }^{1,4}$ The lower mortality rate in the current study may be explained by the spectrum of the variants with predominant missense mutations while the majority of the subjects in the other Saudi study carry a common null mutation. ${ }^{10}$

Study limitations. The relatively small sample size and the fact that we were unable to measure the VLCAD enzyme level which could have ascertained our findings more. Nevertheless, this study broadens the molecular spectrum of VLCAD deficiency in Saudi population. It also gives some phenotype/genotype correlation.

In conclusion, the clinical, biochemical, and molecular data of this study on patients with VLCAD deficiency indicate that their phenotype is variable and their mortality rate is lower compared to the previous Saudi reports. The molecular spectrum observed in this study broadens the genotype of VLCAD deficiency in Saudi patients and gives some phenotype genotype correlation. This study might explain the discrepancies between this and other similar reports, particularly those related to the phenotype and the mortality rate.
Acknowledgment. The authors would like to thank the Prince Abdullah bin Khalid Celiac Disease Research Chair, Vice Deanship of Scientific Research Chairs, King Saud University, Riyadh, Saudi Arabia, for support. We would also like to thank The American Journal Expert for English language editing.

\section{References}

1. Leslie ND, Valencia CA, Strauss AW, Connor JA, Zhang $\mathrm{K}$, Ardinger $\mathrm{HH}$, et al. Very long-chain acyl-Coenzyme A dehydrogenase deficiency. In: GeneReviews ${ }^{\oplus}$ [Internet]. Seattle (WA): University of Washington, Seattle; 1993-2020.

2. Alfadhel M, Benmeakel M, Hossain MA, Al Mutairi F, Al Othaim A, Alfares AA, et al. Thirteen-year retrospective review of the spectrum of inborn errors of metabolism presenting in a tertiary center in Saudi Arabia. Orphanet J Rare Dis 2016; 11: 126.

3. Wilcken B. Fatty acid oxidation disorders: Outcome and long-term prognosis. J Inherit Metab Dis 2010; 33: 501-506.

4. Andresen BS, Olpin S, Poorthuis BJ, Scholte HR, VianeySaban C, Wanders R, et al. Clear correlation of genotype with disease phenotype in very-long-chain acyl-CoA dehydrogenase deficiency. Am J Hum Genet 1999; 64: 479-494.

5. Pena LD, van Calcar SC, Hansen J, Edick MJ, Walsh Vockley C, Leslie N, et al. Outcomes and genotype-phenotype correlations in 52 individuals with VLCAD deficiency diagnosed by NBS and enrolled in the IBEM-IS database. Mol Genet Metab 2016; 118: 272-281.

6. Miller MJ, Burrage LC, Gibson JB, Strenk ME, Lose EJ, Bick DP, et al. Recurrent $A C A D V L$ molecular findings in individuals with a positive newborn screen for very long-chain acyl-CoA dehydrogenase (VLCAD) deficiency in the United States. Mol Genet Metab 2015; 116: 139-145.

7. Lindner M, Hoffmann GF, Matern D. NBS for disorders of fatty-acid oxidation: experience and recommendations from an expert meeting. J Inherit Metab Dis 2010; 33: 521-526.

8. Merritt JL, Vedal S, Abdenur JE, Au SM, Barshop BA, Feuchtbaum L, Harding CO, Hermerath C, Lorey F, Sesser DE, Thompson JD, Yu A. Infants suspected to have very-long-chain acyl-CoA dehydrogenase deficiency from newborn screening. Mol Genet Metab 2014; 111: 484-492.

9. Evans M, Andresen BS, Nation J, Boneh A. VLCAD deficiency: Follow-up and outcome of patients diagnosed through newborn screening in Victoria. Mol Genet Metab 2016; 118: 282-287.

10. Obaid A, Nashabat M, Alfadhl M, et al. Clinical, biochemical, and molecular features in 37 Saudi patients with very longchain acyl- CoA dehydrogenase deficiency. J Inherit Metab Dis 2017; 40: 47-53.

11. Watanabe H, Orii KE, Fukao T, Song XQ, Aoyama T, IJlst L, et al. Molecular basis of very long chain acyl-CoA dehydrogenase deficiency in three Israeli patients: identification of a complex mutant allele with P65L and K247Q mutations, the former being an exonic mutation causing exon 3 skipping. Hum Mutat 2000; 15: 430-438.

12. Andresen BS, Bross P, Vianey-Saban C, et al. Cloning and characterization of human very-long-chain acyl-CoA dehydrogenase cDNA, chromosomal assignment of the gene and identification in four patients of nine different mutations within the VLCAD gene. Hum Mol Genet 1996; 5: 461-472. 
13. Souri M, Aoyama T, Hoganson G, Hashimoto T. Very-longchain acyl-CoA dehydrogenase subunit assembles to the dimer form on mitochondrial inner membrane. FEBS Lett 1998; 426: 187-190.

14. Hisahara S, Matsushita T, Furuyama H, Tajima G, Shigematsu $\mathrm{Y}$, Imai T, et al. A heterozygous missense mutation in adolescentonset very long-chain acyl-CoA dehydrogenase deficiency with exercise-induced rhabdomyolysis. Tohoku J Exp Med 2015; 235: 305-315.
15. Schiff M, Mohsen AW, Karunanidhi A, McCracken E, Yeasted R, Vockley J. Molecular and cellular pathology of very-longchain acyl-CoA dehydrogenase deficiency. Mol Genet Metab 2013; 109: 21-27.

16. Isackson PJ, Sutton KA, Hostetler KY, et al. Novel mutations in the gene encoding very long-chain acyl-CoA dehydrogenase identified in patients with partial carnitine palmitoyltransferase II deficiency. Muscle Nerve 2013; 47: 224-233.

\section{Illustrations, Figures, Photographs}

All figures or photographs should be submitted in a high resolution (minimum 300 DPI) electronic version saved in jpeg or tiff format. Original hard copies of all figures may be requested when necessary. Photographs will be accepted at the discretion of the Editorial Board. All lettering, arrows, or other artwork must be done by an artist or draftsman. If arrows are used please ensure they appear in a different color to the background color, preferably black with a white border, or white with a black border. If arrows distinguish different items on the figure then different arrow styles should be used ie. long, short, wide, narrow. Written informed consent for publication must accompany any photograph in which the subject can be identified. Written copyright permission, from the publishers, must accompany any illustration that has been previously published. 